\title{
AN AGENT-BASED SIMULATION OF AN ALTERNATIVE PARKING BAY CHOICE STRATEGY
}

\author{
M. Lall ${ }^{*}$
}

\section{ARTICLE INFO}

\section{Article details}

Submitted by authors 21 Jan 2020

Accepted for publication 11 Aug 2020

Available online $\quad 31$ Aug 2020

\section{Contact details \\ * Corresponding author \\ lallm@tut.ac.za}

\section{Author affiliations}

1 Department of Computer Science, Tshwane University of Technology, South Africa

\section{DOI}

http://dx.doi.org/10.7166/31-2-2314

\section{ABSTRACT}

Trying to find a parking space in a parking lot is a routine activity for most people in our society. However, in managing the sustained growth rate in the number of vehicle users, the demand on such parking facilities is likely to remain under constant pressure. Both the users and the management of parking lots use various strategies in dealing with the requirement for suitable parking facilities. This paper presents a computational model using an agent-based modelling technique to simulate two commonly used strategies applied to choosing a parking spot under various demand and supply conditions. The model is unique in the current literature, as it is specifically designed to evaluate the effectiveness of the strategies. The analysis of the experimental results shows that, in most conditions, accepting the first available parking spot and then walking to the destination performed better than driving as close as possible to the destination and then searching for an available parking spot.

\section{OPSOMMING}

Om 'n parkeerplek op te spoor is ' $\mathrm{n}$ roetine aktiwiteit vir die meeste mense in ons samelewing. Die bestuur van die volgehoue groeikoers in die aantal voertuiggebruikers plaas egter die vraag na parkeerfasiliteite onder volgehoue druk. Beide die gebruikers en die bestuur van parkeerterreine gebruik verskeie strategieë om die behoefte aan gepaste parkeerfasiliteite te hanteer. Hierdie artikel bied 'n berekeningsmodel aan met ' $n$ agentgebaseerde modelleringstegniek om twee algemene parkeerpleksoek strategieë te simuleer onderhewig aan verskillende vraag en aanbod toestande. Die model is uniek in die beskikbare literatuur omdat dit spesifiek ontwikkel is om die doeltreffendheid van die strategieë te beoordeel. Ontleding van die eksperimentele resultate toon dat, in die meeste gevalle, die aanvaarding van die eerste beskikbare parkeerplek en dan te loop tot by die eindbestemming beter resultate lewer as om tot by die bestemming te ry en dan vir 'n beskikbare parkeerplek te begin soek.

\section{INTRODUCTION}

With an ever-increasing number of car users on our roads, the demand on parking facilities is constantly under pressure. Congestion and environmental problems such as emission and noise are recognised as consequences of drivers searching for suitable parking [1]. In addition, when the demand for parking is not satisfied, parking shortages may lead to a poor reputation for accessibility and a decrease in the facility's attraction for commuters in that locality. One of the ways in which local government agencies meet the demand for parking is by constructing parking facilities such as parking lots. In order to help such authorities in their planning and decision-making, understanding car drivers' movements in parking lots plays a decisive role [2]. In this respect, simulation methods are considered an invaluable tool to deal with the matter. As previous studies have shown, the main operational mechanisms of traditional simulation models describe people's behaviour through a set of differential equations [3, 4]. It is pointed out, however, that such an equation-based modelling approach has some fundamental weaknesses in dealing with complex real-world systems [5, 6]. For instance, they cannot capture the complexity and individuality of human behaviour. Fortunately, with improvements to the theory of complex systems and to computer technology, the heterogeneous and dynamic characteristics of individuals can be modelled by an agent-based modelling technique [3, 7]. Agent-based models are computerised simulations in which autonomous agents interact, 
based on a set of rules and within an environment specified by the researcher $[7,8,9]$. While these rules and constraints describe predictable behaviour at micro-level, the interactions among agents and their environment often aggregate to create unexpected social patterns [10,11]. It is these emergent patterns that are of interest to decision-makers and the users of parking lots.

From the perspective of the users of parking lots, the probability of finding a parking bay of their choice is important, as it influences their daily activities. Deciding on whether to seek a desirable spot close to the destination (where the spot may be difficult to find) or to park further away (where finding the spot is easier to find) and face a long walk leads to various simple strategies. Two such strategies are examined in this article.

In this paper, an agent-based simulation model, SIMUPARK (SIMUlation of PARKing), is presented to evaluate the effectiveness of the two strategies employed by individuals seeking parking bays in a hypothetical parking lot. These two strategies are referred to as the 'first-available' strategy and the 'closest-first' strategy. In the first-available strategy, upon entering the parking lot individuals occupy the first available parking bay they come across, and then walk to their destinations; whereas, in the closest-first strategy, the individuals drive as close as possible to their destination and then, by working outwards, begin their search for the closest available parking bay. Once an unoccupied bay is found, individuals park their vehicles and walk to their destination. In this paper, the two strategies are analysed for their respective effectiveness under the varying demand and supply conditions of the parking bays. The time to find a suitable parking bay, and the time taken to walk to the target or destination after parking, are used as performance parameters to determine the effectiveness of the strategies. The contributions of this study are twofold: it provides an agent-based model using open source software to simulate individuals seeking parking in a parking lot following a particular strategy, and it compares the effectiveness of the two strategies.

The rest of this paper is organised as follows: Section 2 provides a brief survey of the current research in modelling parking-related activities. Section 3 gives a description of the prototype SIMUPARK system. Section 4 details experiments conducted using the SIMUPARK system to simulate parking strategies, and a discussion of the results. Section 5 presents the conclusion and provides directions for future research.

\section{RELATED WORK}

Recent advances in computer hardware and software have made the modelling and simulation of complex systems more feasible. Studying the modelling of parking phenomena is not new. For example, Hatanaka, Fujimoto and Uosaki [12] developed what is known as PLISM-1 to understand the characteristics of a given parking lot plan by observing the dynamic vehicle movement behaviour and evaluating several parking lot performance indexes. Thompson and Richardson [13] presented an on-street parking search model of motorists. Their model investigates the utility of the car park by analysing the access, waiting, direct, and egress cost components involved. In another study, Spitaels and Maerivoet [14] created the SUSTAPARK model for simulating various on-road parking and mobility policies. At its core is a heuristic model of the parking behaviour and strategic decisions of drivers. This model is applied to Leuven (Belgium), and its results are intended to support policy-makers in their decisions about parking and mobility. Parking search in a car park has been represented by the PARKSIM model [15], in which the behaviour of parkers in parking lots is modelled in great detail to aid in the design of new parking lots. Yan, Levine and Marans [16] have created a model of travel mode and parking location choice, using survey data on a large university campus. The variables they examined included parking cost, parking search time, and egress time.

The traditional traffic assignments and parking selection models mentioned above do not reflect the dynamic and micro-behaviour of individuals in the parking process [3, 17]. However, an agent-based simulation model can display the complex space-time relationship of individuals (vehicles) on the road network and the decision-making process of drivers. There are several recent studies involving agent-based models for parking in the current literature. Agent-based modelling in the context of traffic and transportation, including parking-related phenomena, is significant and numerous $[18,19]$. For example, Bonsall and Palmer [20] used the PARKIT parking choice simulator to provide an experimental environment, incorporating parking guidance and information systems, in which drivers' choice of car parks and of the routes to reach them could be observed. Another application of micro-simulation is the PARKAGENT model [21]. It is an agent-based model developed as an ArcGIS extension that is used to simulate the on-street parking behaviour of drivers in Tel Aviv City. Mei, Zhang, Zhang and Wang [22] applied agent-based modelling to manage and configure the parking reservation system by optimising social benefits and parking lot revenue in Hangzhou, China. However, these studies have focused on simulating the dynamics of the 
whole parking process or the choice of parking facility, but not on car drivers' movement across parking lots.

Drivers' movement across or within a parking lot using agent-based modelling and simulation has been researched by Vo, Van Der Waerden and Wets [23]. In their model, ticket payment, the driver's gender, and the size of the car are used as factors for choosing a particular parking bay and analysing their impact on parking management [23]. The model is developed using the Netlogo toolkit [24]. The similarity between the model proposed by Vo, Van Der Waerden and Wets [23] and the SIMUPARK model (i.e., the model proposed in this paper) is that both simulate drivers' movement in a parking lot and have been created using the Netlogo environment. However, the purpose of the proposed model is to evaluate the two strategies described in the previous section. Netlogo has been used because it is open source software and can be downloaded free of charge for all commonly used operating systems [4, 25]. In addition, Netlogo's BehaviorSpace provides an extremely useful tool for automating the running of simulation experiments [7]. It has proven its usefulness in a wide range of research fields [3].

The next section describes the proposed SIMUPARK model using the 'overview, design concepts and details' (ODD) protocol proposed by Grimm et al. [26, 27]. The scientific community regards the ODD protocol as a standardised protocol for describing agent-based models [28].

In this section the application of the ODD protocol to describe the proposed SIMUPARK model is presented. Figure 1 shows the layout of the parking lot. The black and red patches are the aisles along which individual vehicles move. The white patches are the occupied parking bays, and the blue patches are the vacant parking bays. Vehicles enter the parking lot from the bottom left corner and exit at the bottom right corner. The top edge is the destination.

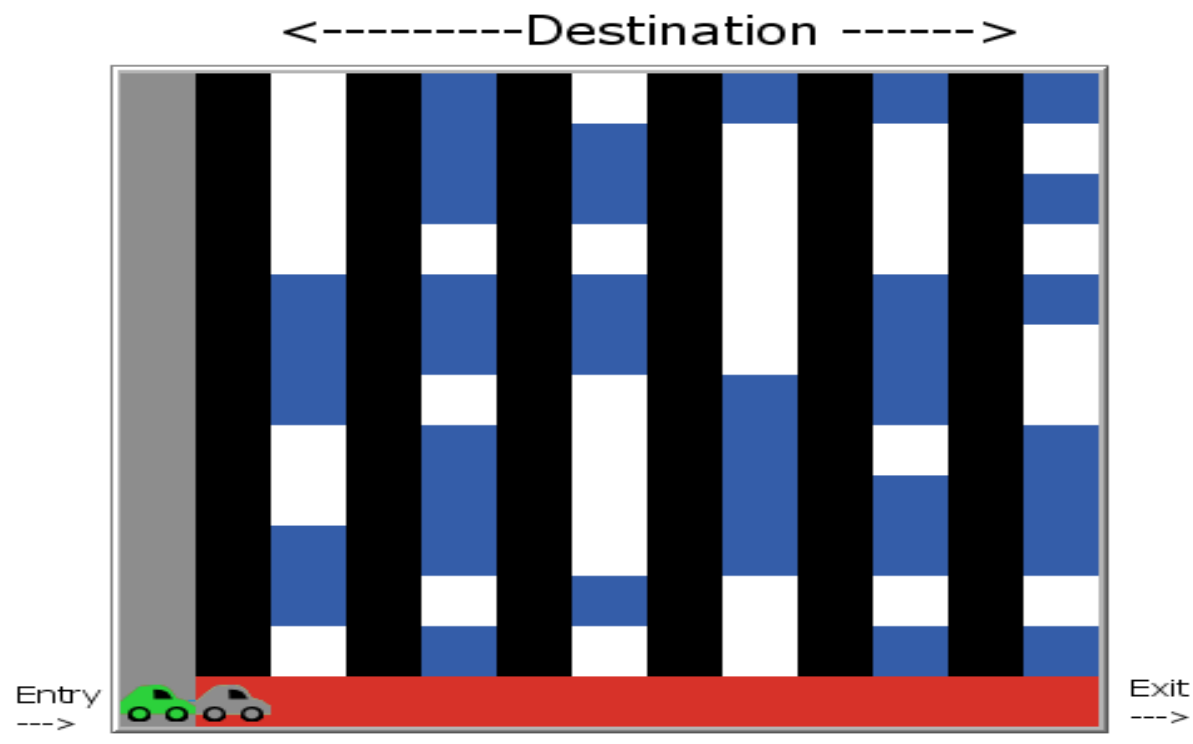

Figure 1: Layout of a hypothetical parking lot used in SIMUPARK

\subsection{Model overview}

Purpose: The purpose of this model is to compare and analyse the effect of two particular types of parking bay choice strategy used by rational individuals in a hypothetical parking lot, under varying demand and supply conditions. The two choice strategies investigated are the 'first-available' strategy and the 'closestfirst' strategy, as previously discussed. The measures of 'effectiveness' include the average time to find a suitable parking bay and the average time taken to walk to the target or destination after parking.

Entities, state variables and scales: The model makes use of two types of agent: stationary and mobile. The stationary agents (or 'patches' in the Netlogo vocabulary) represent the aisles and the parking bays in a parking lot. The mobile agents (referred to as 'turtles' in Netlogo) represent the individuals seeking parking bays. The individuals are shown as cars in the model. The stationary agents are differentiated by 
their colour: white patches indicate that a particular parking bay is occupied, while blue patches indicate the available parking bays, and black and red patches depict the aisles. Individuals seeking parking bays are represented by cars. The individual agents have two state variables: the time ('ticks' in Netlogo) taken to find an empty parking bay after entering the parking lot, and the distance it is parked from the destination. The parking lot is constructed on a square lattice of $13 \times 13$ patches, with 72 parking bays arranged in six rows of 12 parking bays each and with no wrapping at its edges. In addition, the parking lot has one entrance, one exit, and a destination (see Figure 1). The model stops when all the individuals have found a parking bay or all the parking bays have been taken.

Process overview and scheduling: The model includes the following actions, executed in the following order in each time step:

- Moving-about: Once individual agents enter the parking lot, they decide whether to turn left into the first aisle or move forward and turn into the following aisle. This decision is a stochastic one. Depending on the strategy used, the individual agent either begins the search for an empty parking bay or continues to travel on the aisle until they reach the destination and then begin to look for an unoccupied parking bay. Once an unoccupied parking bay is identified, the individual agent turns into the parking bay and parks. Only one individual agent can occupy a parking bay at a time, and the repositioning action of the individual agent is in a random order. On each time step, the distance travelled before coming to rest in a parking bay and the distance to the target or destination are updated for each individual agent.

- $\quad$ Output: The parking lot display and the plot indicating the number of agents that have found parking successfully, and the rate at which parking was found, are updated constantly.

\subsection{Model design}

The design concepts of the model involve the following:

- $\quad$ Basic principles: The basic concept explored in the model is competition between individual agents for parking bays, following a particular strategy.

- Emergence: The primary model result of interest is the average time taken to reach the destination, which emerges from the strategies used by individual agents as they compete for available parking bays distributed randomly. The average time to reach the destination emerges from the number of available parking bays, the number of individuals initialised, and the ratio of vehicle speed to walking speed.

- Observation: At each time step, the number of individuals who have found parking and the rate at which the parking bays are found are displayed graphically. In addition, to understand how the system is working, the distance travelled by individual agents before they find a parking bay, the distance of the parking bay from the destination, and the time taken to find parking are saved so that relevant statistics can be obtained.

- Sensing: The agents are able to sense whether the patch ahead is an aisle or a parking bay. In addition, the agents are able to sense whether or not the bay is occupied.

- $\quad$ Observations: In addition to the visual display of individual behaviour, scatter plots are produced to display the number of individuals who have successfully found parking bays, and the rate at which they were able to do so.

- $\quad$ Adaptive behaviour: The individual agents in this model follow the simple rules governed by the strategies, and so do not have any adaptive behaviour.

- Interaction: The individual agents interact with each other to check whether the parking bay in their neighbourhood has been taken.

- Stochasticity: There are three stochastic elements in the model: first, the initial setup of the unoccupied parking bays; second, the agents' decision whether to enter the first aisle they come across or to move straight ahead and choose the next aisle; and third, the order in which the agents move in search of an empty bay.

\subsection{Model details}

- Initialisation: The patches in the model are assigned different colours to indicate aisles and parking bays. In addition, a certain number of these parking bays, as determined by the user, are randomly selected and marked as unoccupied parking bays. The rest of the parking bays are set as occupied. A user-defined number of individual agents is created at the entrance of the parking lot. The timer is set to zero. At each time step, the individual agents move one unit distance in search of a parking bay. The 'setup' button is used to initialise the simulation environment and the 'go' button to run or 
stop the simulation. The three sliders - num-cars, car-walk-ratio, and num-empty-bays - allow the researcher to vary the input into the model. The term 'num-cars' denotes the number of individuals seeking parking; the 'car-walk-ratio' is the ratio of the average speed of cars moving in the parking lot to the average speed of individuals walking to the destination; and 'num-empty-bays' denotes the number of empty parking bays available in the parking lot. Table 1 shows these variables and their values/range of values used in the simulation.

- Submodels: Since all of the submodels are very simple, their descriptions have already been included in the process overview earlier in this section.

- Input data: The model does not use any external input.

Table 1: Input and initial parameters

\begin{tabular}{|l|l|}
\hline Variables & Default values / range \\
\hline Num-cars & $1-100$ \\
\hline Num-empty-bays & $1-72$ (i.e. car park capacity) \\
\hline Car-walk-ratio & $0.6-1.4$ \\
\hline Strategy-type & First-available / Closest-first \\
\hline
\end{tabular}

\section{EXPERIMENTS AND DISCUSSIONS}

The model was implemented in NetLogo 6.0.4, and the experiments were designed using Netlogo's BehaviourSpace. Microsoft Excel was used to visualise the data. Figure 2 shows the operational interface of the model.
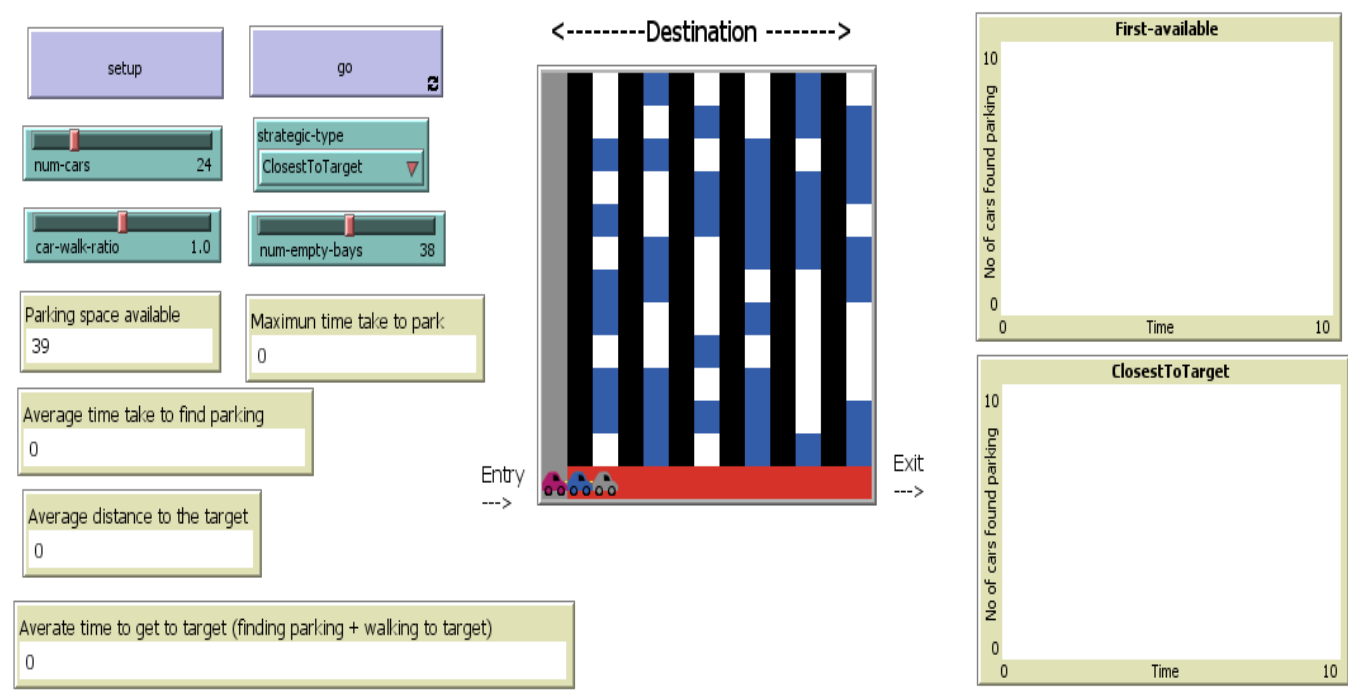

Figure 2: Interface of SIMUPARK model

The dropdown list allows one of the strategies to be selected. Figure 3 shows the simulation run for both strategies after 15 and 25 steps. As can be seen from Figure 3, by using the first-available strategy the agents begin to occupy the available parking bays from the bottom to the top as they move along the aisle; while those using the closest-first strategy move to the destination and then begin to occupy the bays on their return, from the top to the bottom. 


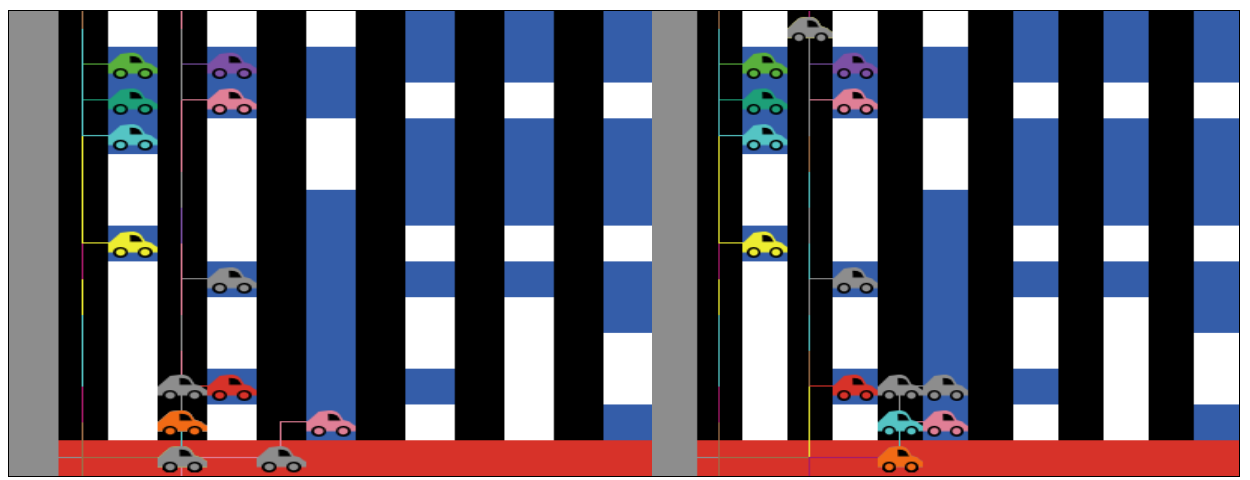

(a)

(b)

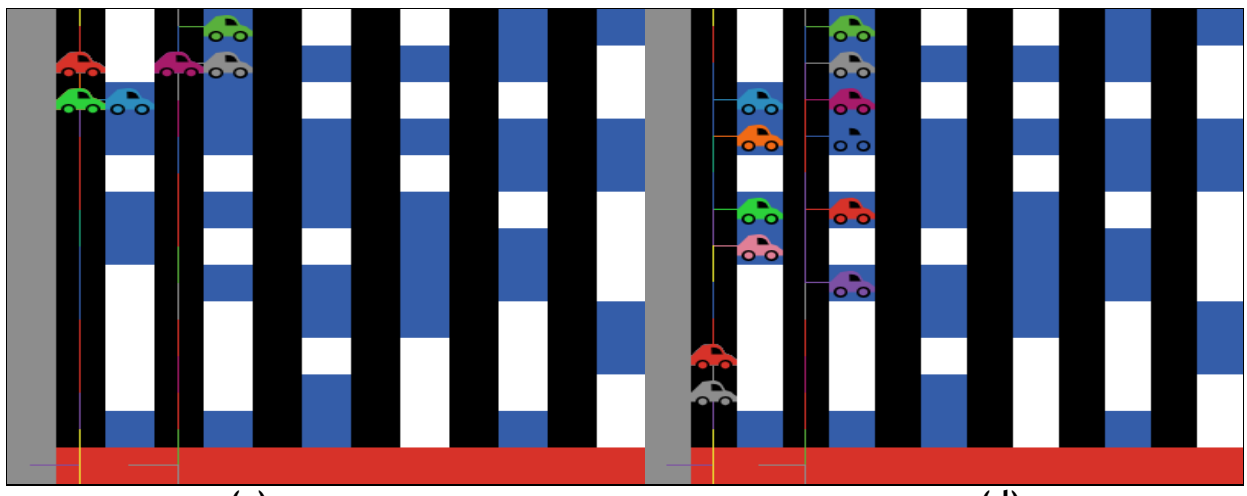

(c)

(d)

Figure 3: Snapshot of the simulation process in different strategies:

(a) and (b) simulation after 15 and 25 ticks using first-available strategy; and (c) and (d) simulation after 15 and 25 ticks using closest-first strategy.

For each run of the simulation, a plot indicating the number of cars that have found parking (shown in red) at each time interval, and the rate at which the parking is found (shown in blue), are drawn for the selected strategy (see Figure 4).

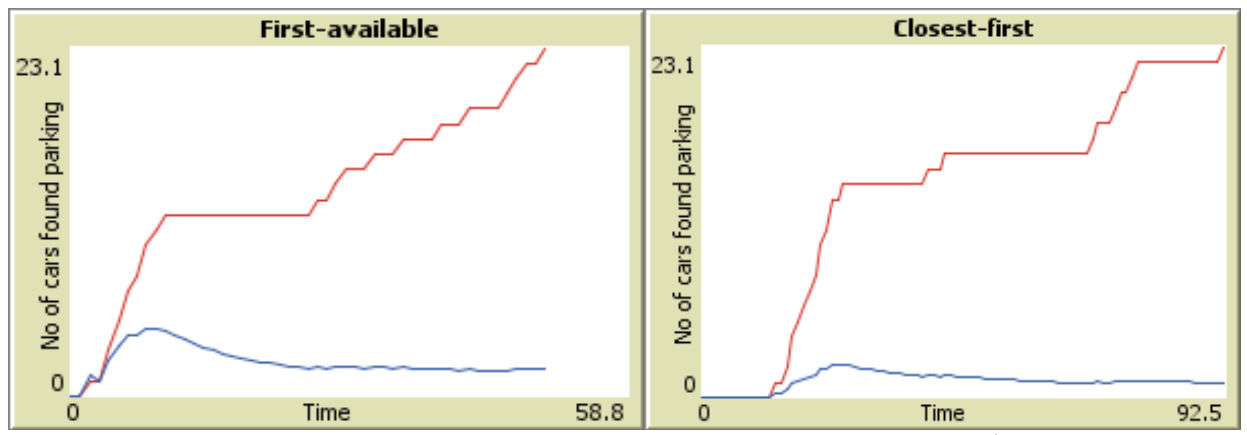

(a)

(b)

Figure 4: Number of cars that found parking at a particular time, and the rate of finding parking using (a) first-available strategy; and (b) closest-first strategy

A few elements of the model are stochastic in nature. For instance, the placement of unoccupied parking bays is random and varies every time the model is initialised, despite the environment and parameter specifications being the same. Thus two runs of the simulation may produce very different results. Because of this, the simulation was run 10 times, and the results were averaged. At the start of each experiment, the number of available parking bays was kept constant at 40 , the number of individuals seeking parking was varied from 4 to 40 , and the car-to-walk ratio was varied from 0.6 to 1.4 . 
As already mentioned, the aim was to compare the effectiveness of two parking strategies under varying conditions. Figure 5 shows the comparison of the average time taken to find parking under varying parking lot occupancy conditions using the two strategies.

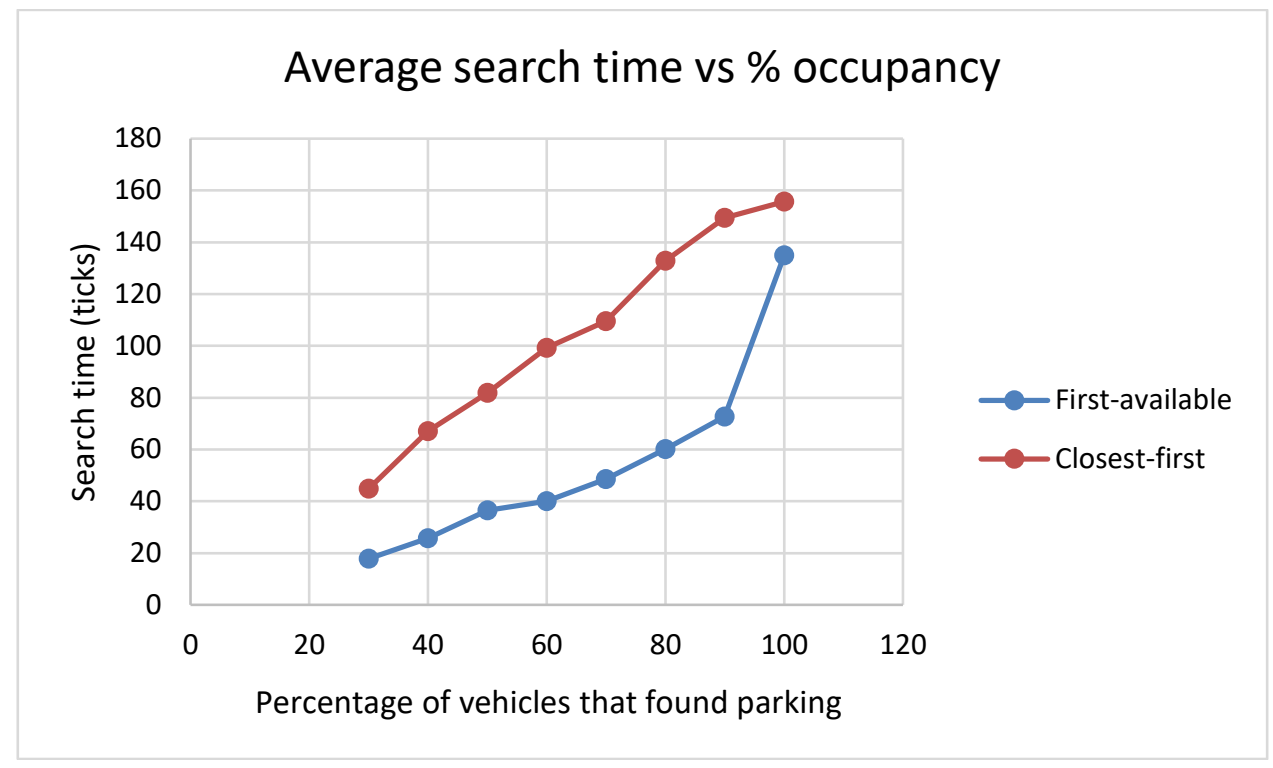

Figure 5: Average parking search time using the two strategies

As is apparent from Figure 5, the time taken to find parking increases in a linear fashion for both strategies. However, in applying the first-available strategy, the time to find parking increased rapidly for the last 10 per cent of individuals. With respect to the time required to search for parking, applying the first-available strategy is observed to perform better.

Another important measure of the effectiveness of the two strategies is the average distance from the destination at which parking is found. Figure 6 shows a comparison of the strategies in this regard.

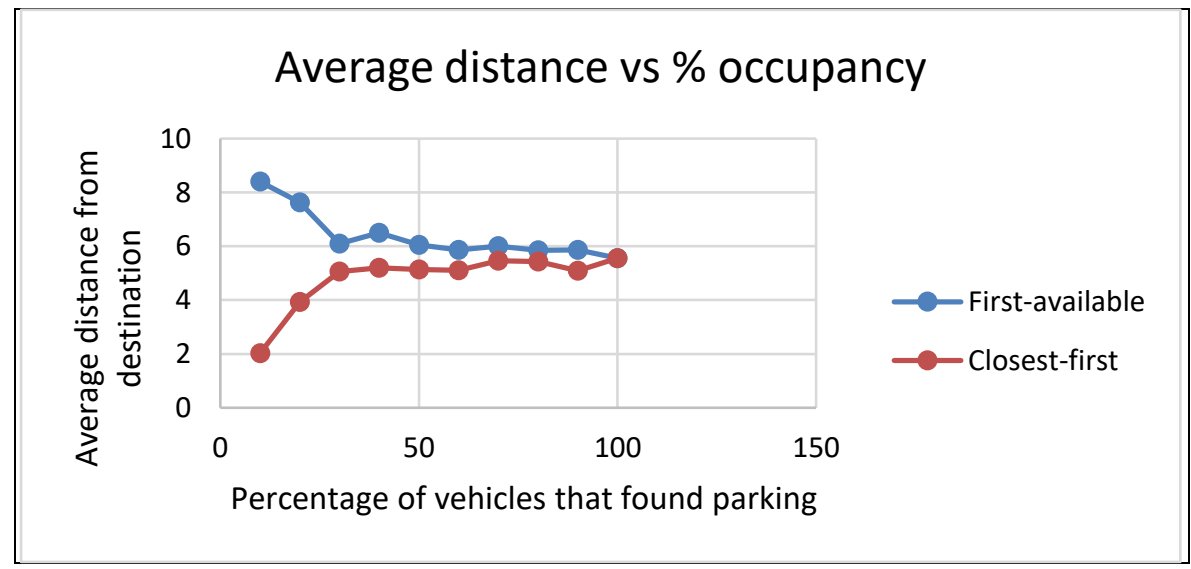

Figure 6: Average distance of the parking from the destination

From Figure 6 it is observed that, for the first 30 per cent of the vehicles, there is a substantive difference between applying the two strategies. However, the difference diminishes as the number of vehicles looking for parking increases.

To compare the strategies for their overall effectiveness, the average total time to find parking and then walk to the destination is used. The total time to destination is derived from the different speeds of walking and driving. The experiments have been performed under varying driving-to-walking ratios. Figure 7 shows the results of the experiments in this regard. 


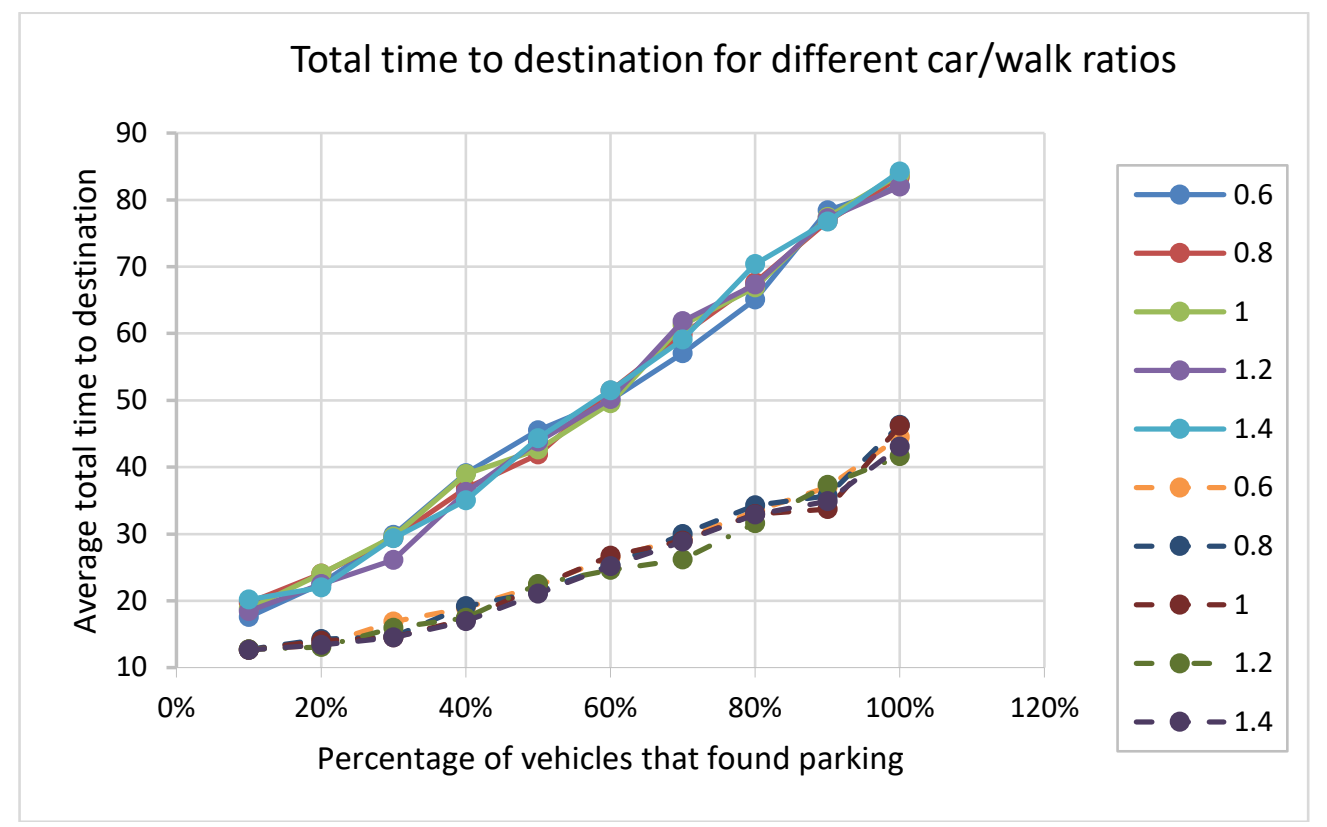

Figure 7: Average time to search and walk to destination

The solid lines in the graph show the average total time taken for the closest-first strategy under different drive-to-walk speed ratios, while the dotted lines are for the first-available strategy. From Figure 7, it is observed that, although the difference between the two strategies in the time taken to find parking is not that big for a small number of vehicles, the difference increases steadily as the number of vehicles increases. The first-available strategy performs better, and has a lower average total time than the closestfirst strategy.

\section{CONCLUSION AND FUTURE RESEARCH}

In this paper a computation model was built to evaluate the effectiveness of the two identified strategies in choosing a parking bay under various demand and supply conditions. The micro-level interactions among agents and their environment were simulated using Netlogo for a hypothetical parking lot. Several simulation experiments were conducted to evaluate the effectiveness of the strategies by varying the parking lot parameters. The detailed analysis of the simulation results shows that applying the firstavailable strategy performed better against most of the performance parameters used in this research.

The use of agent-based modelling software such as Netlogo to simulate movements in a parking lot can serve as a useful tool for evaluating various strategies, both for users and for the management of the parking lot.

The SIMUPARK model can be extended in several ways. For instance, the individual agents can incorporate behaviour that is more intelligent. This behaviour could entail the individual agents being able to decide dynamically on their strategies depending on the current demand and supply conditions, or from their past experiences. Another interesting extension would be to incorporate age and health as additional attributes of the agents, as this is likely to influence an agent's decision in selecting a strategy.

\section{REFERENCES}

[1] Arnott, R. \& Rowse, J. 1999. Modeling parking. Journal of Urban Economics, 45(1), pp. 97-124.

[2] Van der Waerden, P., Timmermans, H. \& da Silva, A.N.R. 2015. The influence of personal and trip characteristics on habitual parking behavior. Case Studies on Transport Policy, 3(1), pp. 33-36.

[3] Macal, C.M. \& North, M.J. 2009. Agent-based modeling and simulation. Proceedings of the 2009 Winter Simulation Conference (WSC), pp. 86-98.

[4] Wilensky, U. \& Rand, W. 2015. An introduction to agent-based modeling: Modeling natural, social, and engineered complex systems with NetLogo. MIT Press.

[5] Sabzian, H., Shafia, M.A., Maleki, A., Hashemi, S.M.S., Baghaei, A. \& Gharib, H. 2019. Theories and practice of agent based modeling: Some practical implications for economic planners. arXiv preprint arXiv:1901.08932.

[6] Sterman, J. 2018. System dynamics at sixty: The path forward. System Dynamics Review, 34, pp. 5-47. 
[7] Railsback, S.F. \& Grimm, V. 2019. Agent-based and individual-based modeling: A practical introduction, $2^{\text {nd }}$ Edition, Princeton University Press, New Jersey.

[8] Farmer, J.D. \& Foley, D. 2009. The economy needs agent-based modelling. Nature, 460, pp. 685-686.

[9] Tracy, M., Cerdá, M. \& Keyes, K.M. 2018. Agent-based modeling in public health: Current applications and future directions. Annual Review of Public Health, 39, pp. 77-94.

[10] Macal, C.M. 2016. Everything you need to know about agent-based modelling and simulation. Journal of Simulation, 10(2), pp. 144-156.

[11] Macal, C.M. \& North, M.J. 2007. Agent-based modeling and simulation: Desktop ABMS. IEEE Winter Simulation Conference, Washington D.C, pp. 95-106.

[12] Hatanaka, T., Fujimoto, T. \& Uosaki, K. 1996. Parking lot simulation system PLISM-1, $13^{\text {th }}$ Triennial World Congress, San Francisco, USA, , 29(1), pp. 7638-7643.

[13] Thompson, R.G. \& Richardson, A.J. 1998. A parking search model. Transportation Research Part A: Policy and Practice, 32(3), pp. 159-170.

[14] Spitaels, K. \& Maerivoet, S. 2008. An empirical agent-based model of parking behaviour. Kumho-Nectar Conference.

[15] Young, W., Thompson, R.G. \& Taylor, M. 1991. A review of urban car parking models. Transport Reviews, 11(1), pp. 63-84.

[16] Yan, X., Levine, J. \& Marans, R. 2019. The effectiveness of parking policies to reduce parking demand pressure and car use. Transport Policy, 73, pp. 41-50.

[17] Mei, Z., Feng, C., Ding, W., Zhang, L. \& Wang, D. 2019. Better lucky than rich? Comparative analysis of parking reservation and parking charge. Transport Policy, 75, pp. 47-56.

[18] Bazzan, A.L. \& Klügl, F. 2014. A review on agent-based technology for traffic and transportation. The Knowledge Engineering Review, 29(3), pp. 375-403.

[19] Maggi, E. \& Vallino, E. 2016. Understanding urban mobility and the impact of public policies: The role of the agent-based models. Research in Transportation Economics, 55, pp. 50-59.

[20] Bonsall, P. \& Palmer, I. 2004. Modelling drivers' car parking behaviour using data from a travel choice simulator. Transportation Research Part C: Emerging Technologies, 12(5), pp. 321-347.

[21] Benenson, I., Martens, K. \& Birfir, S. 2008. PARKAGENT: An agent-based model of parking in the city. Computers, Environment and Urban Systems, 32(6), pp. 431-439.

[22] Mei, Z., Zhang, W., Zhang, L. \& Wang, D. 2020. Optimization of reservation parking space configurations in city centers through an agent-based simulation. Simulation Modelling Practice and Theory, 99, 102020.

[23] Vo, T.T.A., van der Waerden, P. \& Wets, G. 2016. Micro-simulation of car drivers' movements at parking lots. Procedia Engineering, 142, pp. 100-107.

[24] Northwestern University. 1999. NetLogo. Center for Connected Learning and Computer-Based Modeling. http://ccl.northwestern.edu/netlogo/. [Accessed December 2019].

[25] Sklar, E. 2007. NetLogo, a multi-agent simulation environment. Artificial Life, 13(3), pp. 303-311.

[26] Grimm, V., Berger, U., Bastiansen, F., Eliassen, S., Ginot, V., Giske, J., Goss-Custard, J., Grand, T., Heinz, S.K. \& Huse, G. 2006. A standard protocol for describing individual-based and agent-based models. Ecological Modelling, 198(1), pp. 115-126.

[27] Grimm, V., Berger, U., Deangelis, D.L., Polhill, J.G., Giske, J. \& Railsback, S.F. 2010. The ODD protocol: A review and first update. Ecological Modelling, 221(23), pp. 2760-2768.

[28] Müller, B., Bohn, F., Dreßler, G., Groeneveld, J., Klassert, C., Martin, R., Schluiter, M., Schulze, J., Weise, H. \& Schwarz, N. 2013. Describing human decisions in agent-based models: ODD+D, an extension of the ODD protocol. Environmental Modelling \& Software, 48, pp. 37-48. 